\title{
PERIODICITY IN IMPULSIVE PREDATOR-PREY SYSTEM WITH HOLLING III FUNCTIONAL RESPONSE
}

\author{
Dan Ye AND Meng FAN ${ }^{\dagger}$
}

\begin{abstract}
With the help of the continuation theorem in coincidence degree theory, we establish the existence of positive periodic solutions of impulsive predator-prey system with Holling III functional response.
\end{abstract}

\section{Introduction}

Recently, many authors devoted themselves to investigate the dynamics of nonautomous predator-prey system with periodic parameters and achieved many results, see for example $[3-6,9,11,17,19]$. As we all know, the predator-prey systems with Holling III functional response possess an important role in the predator-prey theory. Some authors have shown great interest in such systems with periodic parameters. For example, Jia [9] has investigated predator-prey model with Holling III functional response [8].

$$
\begin{aligned}
& y_{1}^{\prime}(t)=y_{1}(t)\left(a_{1}(t)-a_{11}(t) y_{1}(t)-\frac{a_{12}(t) y_{1}(t) y_{2}(t)}{a_{13}^{2}(t)+y_{1}^{2}(t)}\right), \\
& y_{2}^{\prime}(t)=y_{2}(t)\left(-a_{2}(t)-a_{21}(t) y_{2}(t)+\frac{a_{22}(t) y_{1}^{2}(t)}{a_{13}^{2}(t)+y_{1}^{2}(t)}\right),
\end{aligned}
$$

and derived sufficient conditions for the persistence and the existence of periodic solutions.

In 2002, following the idea and the method of [6], Zhang [19] derives sufficient criteria for the existence of positive periodic solution of the discrete analogue of (1.1) governed by nonautomous difference equation with periodic parameters.

Key Words: Positive periodic solution, predator-prey system, Holling III functional response, coincidence degree, impulse.

MR (2000) Subject Classification: 34K45, 34K13, 92D25.

* Supported by the National Natural Science Foundation of P. R. China (No. 10171010 and 10201005), the Key Project on Science and Technology of the Education Ministry of P. R. China (No. Key 01061) and the Science Foundation of Jilin Province of P. R. China for Distinguished Young Scholars.

†Corresponding author.

Received April 7, 2003. 
However, almost all the work on the predator-prey systems with Holling III functional response neglect the practical effects of some important impulsive factors existing in the real world. The birth of many populations is not continuous but happens at some regular time, for example, the birth of many wildlife is seasonal. The birth of population at those time can be viewed as impulse to the population. Another typical impulse is the harvest and stock of the population explored by human beings. If one incorporate such impulsive factors into the mathematical models modelling the population interactions, those models must be impulsive and governed by impulsive deferential equations $[1,2,10,12$ $16,18]$.

The principal aim of this paper is to incorporate impulsive factors into system (1.1) and establish sufficient criteria for the existence of positive periodic solution of the following system

$$
\begin{gathered}
y_{1}^{\prime}(t)=y_{1}(t)\left(-d_{1}(t)-a_{11}(t) y_{1}(t)-\frac{a_{12}(t) y_{1}(t) y_{2}(t)}{a_{13}^{2}(t)+y_{1}^{2}(t)}\right), \quad t \neq t_{k}, k=1,2 \ldots \\
y_{2}^{\prime}(t)=y_{2}(t)\left(-d_{2}(t)-a_{21}(t) y_{2}(t)+\frac{a_{22}(t) y_{1}^{2}(t)}{a_{13}^{2}(t)+y_{1}^{2}(t)}\right), \quad t \neq t_{k}, k=1,2 \ldots \\
\triangle y_{i}(t)=y_{i}\left(t^{+}\right)-y_{i}\left(t^{-}\right)=\left(b_{i k}+h_{i k}\right) y_{i}(t), \quad t=t_{k}, y_{i}(0)=y_{i 0}, i=1,2,
\end{gathered}
$$

where $b_{i k}, h_{i k}$ stand for birth rate and harvesting (stocking) rate of $y_{i}$ at time $t_{k}$, respectively; $d_{1}(t)$ is the death rate of the prey and $d_{2}(t)$ is that of the predator. Other parameters have the same meaning as that in (1.1). When $h_{i k}>0$, it stands for stocking, while $h_{i k}<0$ means harvesting. $y_{i}\left(t_{k}^{+}\right)$and $y_{i}\left(t_{k}^{-}\right)$represent the right and the left limit of $y_{i}$ at $t_{k}$, respectively. In this paper, it is assumed that $y_{i}$ is left-continuous at $t_{k}$.

Assume that

$\left(A_{1}\right) b_{i k} \geq 0, \quad b_{i k}+h_{i k} \geq 0$, and $d_{i}(t), a_{i j}(t)(i=1,2 ; j=1,2,3$. $)$ are nonnegative continuous $\omega$-periodic functions

$\left(A_{2}\right)$ there exists a positive integer $q$, such that $t_{k+q}=t_{k+\omega}, \quad b_{i(k+q)}=$ $b_{i k}, h_{i(k+q)}=h_{i k}$. Without loss of generality, we also assume that if $t_{k} \neq 0$ and $[0, \omega] \cap t_{k}=t_{1}, t_{2} \cdots t_{m}$, then it follows that $q=m$.

It is trivial to show that the solutions of (1.2) with positive initial value remain positive too. So, we can make the change of variables

$$
y_{i}(t)=e^{x_{i}(t)}, \quad i=1,2,
$$

and then (1.2) is reformulated as

$$
\begin{aligned}
x_{1}^{\prime}(t) & =-d_{1}(t)-a_{11}(t) e^{x_{1}(t)}-\frac{a_{12}(t) e^{x_{2}(t)+x_{1}(t)}}{a_{13}^{2}(t)+e^{2 x_{1}(t)}}, \quad t \neq t_{k}, k=1,2 \ldots \\
x_{2}^{\prime}(t) & =-d_{2}(t)-a_{21}(t) e^{x_{2}(t)}+\frac{a_{22}(t) e^{2 x_{1}(t)}}{a_{13}^{2}(t)+e^{2 x_{1}(t)}}, \quad t \neq t_{k}, k=1,2 \ldots \\
\triangle x_{i}(t) & =x_{i}\left(t^{+}\right)-x_{i}\left(t^{-}\right)=\ln \left(1+b_{i k}+h_{i k}\right), \quad t=t_{k}, x_{i}(0)=\ln \left\{y_{i 0}\right\}>0, i=1,2 .
\end{aligned}
$$


LEMMA 1.1. If $y(t)=\left(y_{1}(t), y_{2}(t)\right)$ is a positive $\omega$-periodic solution of (1.2), then $x_{i}(t)=\ln \left\{y_{i}(t)\right\}$ is an $\omega$-periodic solutions of (1.3), and vice versa.

Definition 1.1. The mapping $x:[0, \omega] \rightarrow R^{2}$ is called a solution of system (1.3) in $[0, \omega]$, if

(i) $x(t)$ is partly continuous, $t_{k} \cap[0, \omega]$ is discontinuous point of the first kind of $x(t)$ and left continuous.

(ii) $x(t)$ satisfies system $(1.3)$ on $[0, \omega]$.

Definition 1.2. The mapping $x: R \rightarrow R^{2}$ is called an $\omega$-periodic solution of system (1.3), if

(i) $x(t)$ is a solution of (1.3).

(ii) $x(t)$ satisfies $x(t+\omega-0)=x(t-0), t \in R$.

Obviously, if $x(t)$ is a solution of (1.3) satisfying $x(0)=x(\omega)$ in $[0, \omega]$, then from the periodicity of the vector field of (1.3), we know that the function

$$
x^{*}(t)=\left\{\begin{array}{l}
x(t-j \omega), \quad t \in[j \omega,(j+1) \omega] \\
x^{*}(t) \text { is left continuous at } t_{k} .
\end{array}\right.
$$

is an $\omega$-periodic solution of (1.3). So, in order to achieve the existence of periodic solution to (1.3), it is sufficient to find the solutions of $(1.3)$ in $[0, \omega]$ satisfying $x(0)=x(\omega)$. That is to find solutions of the following system in $[0, \omega]$

$$
\begin{aligned}
x_{1}^{\prime}(t) & =-d_{1}(t)-a_{11}(t) e^{x_{1}(t)}-\frac{a_{12}(t) e^{x_{2}(t)+x_{1}(t)}}{a_{13}^{2}(t)+e^{2 x_{1}(t)}}, \quad t \neq t_{k}, k=1,2 \ldots \\
x_{2}^{\prime}(t) & =-d_{2}(t)-a_{21}(t) e^{x_{2}(t)}+\frac{a_{22}(t) e^{2 x_{1}(t)}}{a_{13}^{2}(t)+e^{2 x_{1}(t)}}, \quad t \neq t_{k}, k=1,2 \ldots \\
\triangle x_{i}(t) & =x_{i}\left(t^{+}\right)-x_{i}\left(t^{-}\right)=\ln \left(1+b_{i k}+h_{i k}\right), \quad t=t_{k}, x_{i}(0)=x_{i}(\omega)>0, i=1,2 .
\end{aligned}
$$

For simplicity and convenience in the following discussion, throughout this paper, we will use the notation

$$
\bar{f}:=\frac{1}{\omega} \int_{0}^{\omega} f(t) d t
$$

where $f$ is $\omega$-periodic.

\section{Existence of periodic solution}

In order to obtain the existence of positive periodic solution of (1.2), for the readers' convenience, we shall present below a few of concepts and results from [7], which will be basic for this section.

Let $X, Z$ be normed vector spaces, $L:$ Dom $L \subset X \rightarrow Z$ be a linear mapping, $N: X \rightarrow Z$ be a continuous mapping. The mapping $L$ will be called a Fredholm mapping of index zero if $\operatorname{dim} \operatorname{Ker} L=\operatorname{codim} \operatorname{Im} L<+\infty$ and $\operatorname{Im} L$ 
is closed in $Z$. If $L$ is a Fredholm mapping of index zero and there exist continuous projectors $P: X \rightarrow X$ and $Q: Z \rightarrow Z$ such that $\operatorname{Im} P=\operatorname{Ker} L$, $\operatorname{Im} L=\operatorname{Ker} Q=\operatorname{Im}(I-Q)$, it follows that $L \mid \operatorname{Dom} L \cap \operatorname{Ker} P:(I-P) X \rightarrow \operatorname{Im} L$ is invertible. We denote the inverse of that map by $K_{P}$. If $\Omega$ is an open bounded subset of $X$, the mapping $N$ will be called $L$-compact on $\bar{\Omega}$ if $Q N(\bar{\Omega})$ is bounded and $K_{P}(I-Q) N: \bar{\Omega} \rightarrow X$ is compact. Since $\operatorname{Im} Q$ is isomorphic to Ker $L$, there exists an isomorphism $J: \operatorname{Im} Q \rightarrow \operatorname{Ker} L$.

Lemma 2.1 (Continuation Theorem). Let $L$ be a Fredholm mapping of index zero and $N$ be L-compact on $\bar{\Omega}$. Suppose

(a) For each $\lambda \in(0,1)$, every solution $x$ of $L x=\lambda N x$ is such that $x \notin \partial \Omega$;

(b) $Q N x \neq 0$ for each $x \in \partial \Omega \cap \operatorname{Ker} L$ and

$$
\operatorname{deg}\{J Q N, \Omega \cap \operatorname{Ker} L, 0\} \neq 0 .
$$

Then the operator equation $L x=N x$ has at least one solution lying in Dom $L \cap \bar{\Omega}$.

Let

$$
\begin{aligned}
& C\left[0, \omega ; t_{1}, t_{2}, \ldots t_{m}\right] \\
& \quad=\left\{\begin{array}{l|l}
x:[0, \omega] \rightarrow R^{2} & \begin{array}{l}
x(t) \text { is continuous with respect to } t \neq t_{1}, \ldots, t_{m} ; \\
x(t+0) \text { and } x(t-0) \text { exist at } t_{1}, \ldots, t_{m} ; \\
x\left(t_{k}\right)=x\left(t_{k}-0\right), \quad k=1,2, \ldots, m
\end{array}
\end{array}\right\}
\end{aligned}
$$

Define

$$
\frac{\sum_{k=1}^{q} \ln \left(1+b_{i k}+h_{i k}\right)}{\omega}-\bar{d}_{i}:=\triangle_{i}, \quad i=1,2 .
$$

Now we are ready to state and prove the main results of the present paper.

THEOREM 2.1. Assume that $\left(A_{1}\right)\left(A_{2}\right)$ hold. Moreover, if $\triangle_{2}>0$ and $\triangle_{1}>\overline{\left(a_{12} / a_{13}^{2}\right)} e^{H_{1}+H_{2}}$, where

$$
\begin{gathered}
H_{1}=\ln \left\{\frac{\triangle_{1}}{\bar{a}_{11}}\right\}+2 \sum_{k=1}^{q} \ln \left(1+b_{1 k}+h_{1 k}\right), \\
H_{2}=\ln \left\{\frac{\bar{a}_{22}+\triangle_{2}}{\bar{a}_{21}}\right\}+2\left(\sum_{k=1}^{q} \ln \left(1+b_{2 k}+h_{2 k}\right)+\bar{a}_{22} \omega\right) .
\end{gathered}
$$

Then system (1.2) has at least one positive w-periodic solution. 
Proof. Let

$$
X=\left\{x=\left(x_{1}, x_{2}\right)^{T} \in C\left[0, \omega ; t_{1}, \ldots t_{m}\right] \mid x(\omega)=x(0)\right\}, \quad Z=X \times R^{2 q} .
$$

Define

$$
\|x\|_{C}=\sup _{t \in[0, \omega]}|x(t)|, \quad\|z\|_{Z}=\|x\|_{C}+\|y\|, \quad x \in X, y \in R^{2 q},
$$

where $|\cdot|$ and $\|\cdot\|$ are norms of $R^{2}$ and $R^{2 q}$, respectively. Then it is trivial to show that $X, Z$ are both Banach spaces when they are endowed with the above norm $\|\cdot\|_{C}$ and $\|\cdot\|_{Z}$, respectively.

Let

$$
\begin{gathered}
\operatorname{dom} L \subset X=\left\{x=\left(x_{1}, x_{2}\right)^{T} \in C\left[0, \omega ; t_{1}, \ldots t_{m}\right] \mid x(\omega)=x(0)\right\}, \\
L: \operatorname{dom} L \rightarrow Z, \quad L x=\left(x^{\prime}, \Delta x\left(t_{1}\right), \ldots, \Delta x\left(t_{m}\right)\right), \\
N: X \rightarrow Z, \\
\left.N x=\left(\begin{array}{c}
-d_{1}(t)-a_{11}(t) e^{x_{1}(t)}-\frac{a_{12}(t) e^{x_{2}(t)+x_{1}(t)}}{a_{13}^{2}(t)+e^{2 x_{1}(t)}} \\
\left.-d_{2}(t)-a_{21}(t) e^{x_{2}(t)}+\frac{a_{22}(t) e^{2 x_{1}(t)}}{a_{13}^{2}(t)+e^{2 x_{1}(t)}}\right)
\end{array}\right), \ldots\left(\begin{array}{l}
\ln \left(1+b_{1 q}+h_{1 q}\right) \\
\ln \left(1+b_{2 q}+h_{2 q}\right)
\end{array}\right)\right)
\end{gathered}
$$

Then

and

$$
\begin{aligned}
\text { Ker } L & =\left\{x: x=A \in R^{2}, t \in[0, \omega]\right\} \\
\operatorname{Im} L & =\left\{z=\left(f, C_{1} \cdots C_{q}\right) \in Z: \int_{0}^{\omega} f(s) d s+\sum_{k=1}^{q} C_{k}=0\right\}
\end{aligned}
$$

$$
\operatorname{dim} \operatorname{Ker} L=2=\operatorname{codim} \operatorname{Im} L .
$$

Since $\operatorname{Im} L$ is closed in $Z, L$ is a Fredholm mapping of index zero. Let

$$
\begin{aligned}
& P x=\frac{1}{\omega} \int_{0}^{\omega} x(t) d t \\
& Q z=Q\left(f, C_{1} \cdots C_{q}\right)=\left(\frac{1}{\omega}\left[\int_{0}^{\omega} f(s) d s+\sum_{k=1}^{q} C_{k}\right], 0 \cdots 0\right) .
\end{aligned}
$$

It is easy to show that $P, Q$ are continuous projectors such that

$$
\operatorname{Im} P=\operatorname{Ker} L, \quad \operatorname{Im} L=\operatorname{Ker} Q=\operatorname{Im}(I-Q) .
$$

Furthermore, the generalized inverse (to $L$ ) $K_{P}: \operatorname{Im} L \rightarrow$ Dom $L \cap \operatorname{Ker} P$ exists. 
Now, we derive the explicit expression for $K_{p}$. Let $z=\left(f, C_{1} \cdots C_{q}\right) \in \operatorname{Im} L$, then $x \in X$ satisfies

Then

$$
\begin{gathered}
x^{\prime}(t)=f(t), \quad t \neq t_{k}, k=1,2 \ldots \\
\left.\triangle x(t)\right|_{t=t_{k}}=C_{k} .
\end{gathered}
$$

$$
x(t)=\int_{0}^{\omega} f(s) d s+\sum_{t>t_{k}} C_{k}+x(0) .
$$

Note that $x(t) \in \operatorname{Ker} P$, i.e., $1 / \omega \int_{0}^{\omega} x(s) d s=0$. From (2.1), we get

$$
\int_{0}^{\omega} \int_{0}^{t} f(s) d s d t+\int_{0}^{\omega} \sum_{t>t_{k}} C_{k} d t+\omega x(0)=0
$$

and hence

$$
x(t)=\int_{0}^{\omega} f(s) d s+\sum_{t>t_{k}} C_{k}-\frac{1}{\omega} \int_{0}^{\omega} \int_{0}^{t} f(s) d s d t-\sum_{t=1}^{q} C_{k} d t,
$$

that is

$$
K_{P} z=\int_{0}^{\omega} f(s) d s+\sum_{t>t_{k}} C_{k}-\frac{1}{\omega} \int_{0}^{\omega} \int_{0}^{t} f(s) d s d t-\sum_{t=1}^{q} C_{k} d t
$$

Thus

$$
Q N x=\left(\begin{array}{c}
\left(\begin{array}{c}
\frac{1}{\omega}\left(\int_{0}^{\omega}\left[-d_{1}(s)-a_{11}(s) e^{x_{1}(s)}-\frac{a_{12}(s) e^{x_{2}(s)+x_{1}(s)}}{a_{13}^{2}(s)+e^{2 x_{1}(s)}}\right] d s\right. \\
\left.+\sum_{k=1}^{q} \ln \left(1+b_{1 k}+h_{1 k}\right)\right) \\
\frac{1}{\omega}\left(\int_{0}^{\omega}\left[-d_{2}(s)-a_{21}(s) e^{x_{2}(s)}+\frac{a_{22}(s) e^{2 x_{1}(s)}}{a_{13}^{2}(s)+e^{2 x_{1}(s)}}\right] d s\right. \\
\left.+\sum_{k=1}^{q} \ln \left(1+b_{2 k}+h_{2 k}\right)\right)
\end{array}\right), 0, \ldots 0
\end{array}\right),
$$

$K_{P}(I-Q) N x$

$$
=\left(\begin{array}{c}
\int_{0}^{t}\left[-d_{1}(s)-a_{11}(s) e^{x_{1}(s)}-\frac{a_{12}(s) e^{x_{2}(s)+x_{1}(s)}}{a_{13}^{2}(s)+e^{2 x_{1}(s)}}\right] d s+\sum_{t>t_{k}}^{q} \ln \left(1+b_{1 k}+h_{1 k}\right) \\
\int_{0}^{t}\left[-d_{2}(s)-a_{21}(s) e^{x_{2}(s)}+\frac{a_{22}(s) e^{2 x_{1}(s)}}{a_{13}^{2}(s)+e^{2 x_{1}(s)}}\right] d s+\sum_{t>t_{k}}^{q} \ln \left(1+b_{2 k}+h_{2 k}\right)
\end{array}\right)
$$




$$
\begin{gathered}
-\left(\begin{array}{c}
\frac{1}{\omega} \int_{0}^{\omega} \int_{0}^{t}\left[-d_{1}(s)-a_{11}(s) e^{x_{1}(s)}-\frac{a_{12}(s) e^{x_{2}(s)+x_{1}(s)}}{a_{13}^{2}(s)+e^{2 x_{1}(s)}}\right] d s d t+\sum_{k=1}^{q} \ln \left(1+b_{1 k}+h_{1 k}\right) \\
\frac{1}{\omega} \int_{0}^{\omega} \int_{0}^{t}\left[-d_{2}(s)-a_{21}(s) e^{x_{2}(s)}+\frac{a_{22}(s) e^{2 x_{1}(s)}}{a_{13}^{2}(s)+e^{2 x_{1}(s)}}\right] d s d t+\sum_{k=1}^{q} \ln \left(1+b_{2 k}+h_{2 k}\right)
\end{array}\right) \\
-\left(\begin{array}{c}
\left(\frac{t}{\omega}-\frac{1}{2}\right)\left(\int_{0}^{t}\left[-d_{1}(s)-a_{11}(s) e^{x_{1}(s)}-\frac{a_{12}(s) e^{x_{2}(s)+x_{1}(s)}}{a_{13}^{2}(s)+e^{2 x_{1}(s)}}\right] d s\right. \\
\left.+\sum_{k=1}^{q} \ln \left(1+b_{1 k}+h_{1 k}\right)\right) \\
\left(\frac{t}{\omega}-\frac{1}{2}\right)\left(\int_{0}^{\omega}\left[-d_{2}(s)-a_{21}(s) e^{x_{2}(s)}+\frac{a_{22}(s) e^{2 x_{1}(s)}}{a_{13}^{2}(s)+e^{2 x_{1}(s)}}\right] d s\right. \\
\left.+\sum_{k=1}^{q} \ln \left(1+b_{2 k}+h_{2 k}\right)\right)
\end{array}\right) .
\end{gathered}
$$

Obviously, $Q N$ and $K_{P}(I-Q) N$ are continuous. It is not difficult to show that $\overline{K_{P}(I-Q) N(\bar{\Omega})}$ is compact for any open bounded set $\Omega \subset X$. Moreover, $Q N(\bar{\Omega})$ is bounded. Thus, $N$ is $L$-compact on $\bar{\Omega}$ with any open bounded set $\Omega \subset X$.

Now we reach the position to search for an appropriate open, bounded subset $\Omega$ for the application of the continuation theorem. Corresponding to the operator equation $L x=\lambda N x, \lambda \in(0,1)$, we have

$$
\begin{aligned}
x_{1}^{\prime}(t) & =\lambda\left[-d_{1}(t)-a_{11}(t) e^{x_{1}(t)}-\frac{a_{12}(t) e^{x_{2}(t)+x_{1}(t)}}{a_{13}^{2}(t)+e^{2 x_{1}(t)}}\right], \quad t \neq t_{k}, k=1,2 \ldots \\
x_{2}^{\prime}(t) & =\lambda\left[-d_{2}(t)-a_{21}(t) e^{x_{2}(t)}+\frac{a_{22}(t) e^{2 x_{1}(t)}}{a_{13}^{2}(t)+e^{2 x_{1}(t)}}\right], \quad t \neq t_{k}, k=1,2 \ldots \\
\triangle x_{i}(t) & =x_{i}\left(t^{+}\right)-x_{i}\left(t^{-}\right)=\lambda \ln \left(1+b_{i k}+h_{i k}\right), \quad t=t_{k}, x_{i}(0)=x_{i}(\omega), i=1,2 .
\end{aligned}
$$

Suppose that $x \in X$ is a solution of system (2.4) for a certain $\lambda \in(0,1)$. Integrating on both sides of (2.4) from 0 to $\omega$, we obtain

$$
\begin{aligned}
\int_{0}^{\omega}\left[a_{11}(t) e^{x_{1}(t)}+\frac{a_{12}(t) e^{x_{2}(t)+x_{1}(t)}}{a_{13}^{2}(t)+e^{2 x_{1}(t)}}\right] d t & =\triangle_{1} \omega, \\
\int_{0}^{\omega}\left[a_{21}(t) e^{x_{2}(t)}-\frac{a_{22}(t) e^{2 x_{1}(t)}}{a_{13}^{2}(t)+e^{2 x_{1}(t)}}\right] d t & =\triangle_{2} \omega .
\end{aligned}
$$

It follows from (2.4) and (2.5) that 


$$
\begin{aligned}
& \int_{0}^{\omega}\left|x_{1}^{\prime}(t)\right| d t \leq \int_{0}^{\omega}\left[d_{1}(t)+a_{11}(t) e^{x_{1}(t)}+\frac{a_{12}(t) e^{x_{2}(t)+x_{1}(t)}}{a_{13}^{2}(t)+e^{2 x_{1}(t)}}\right] d t+\sum_{k=1}^{q} \ln \left(1+b_{1 k}+h_{1 k}\right) \\
& =2 \sum_{k=1}^{q} \ln \left(1+b_{1 k}+h_{1 k}\right) \\
& \int_{0}^{\omega}\left|x_{2}^{\prime}(t)\right| d t \leq \int_{0}^{\omega}\left[d_{2}(t)+a_{21}(t) e^{x_{2}(t)}+\frac{a_{22}(t) e^{2 x_{1}(t)}}{a_{13}^{2}(t)+e^{2 x_{1}(t)}}\right] d t+\sum_{k=1}^{q} \ln \left(1+b_{2 k}+h_{2 k}\right) \\
& =2\left(\sum_{k=1}^{q} \ln \left(1+b_{2 k}+h_{2 k}\right)+\bar{a}_{22} \omega\right) \text {. }
\end{aligned}
$$

Since $x \in X$, there exist $\xi_{i} \in[0, \omega]$ such that

$$
x_{i}\left(\xi_{i}\right)=\min _{t \in[0, \omega]} x_{i}(t), \quad i=1,2 .
$$

On the other hand, note that $\sup _{t \in[0, \omega]} x_{i}(t)$ exist and there exist $\eta_{i} \in[0, \omega]$ such that

$$
x_{i}\left(\eta_{i}^{+}\right)=\sup _{t \in[0, \omega]} x_{i}(t), \quad i=1,2 .
$$

If $\eta_{i} \neq t_{k}$, then $x_{i}\left(\eta_{i}^{+}\right)=x_{i}\left(\eta_{i}\right)$ while if $\eta_{i}=t_{k}$, we have $x_{i}\left(\eta_{i}^{+}\right)=x_{i}\left(t_{k}^{+}\right)$.

From (2.5) and (2.7), we obtain

$$
\begin{aligned}
& \triangle_{1} \omega \geq \int_{0}^{\omega} a_{11}(t) e^{x_{1}\left(\xi_{1}\right)} d t=\bar{a}_{11} \omega e^{x_{1}\left(\xi_{1}\right)}, \\
& \triangle_{2} \omega \geq \int_{0}^{\omega}\left[a_{21}(t) e^{x_{2}\left(\check{\xi}_{2}\right)}-a_{22}(t)\right] d t=\bar{a}_{21} e^{x_{2}\left(\xi_{2}\right)}-\bar{a}_{22},
\end{aligned}
$$

and hence,

$$
x_{1}\left(\xi_{1}\right) \leq \ln \left\{\frac{\triangle_{1}}{\bar{a}_{11}}\right\}, \quad x_{2}\left(\xi_{2}\right) \leq \ln \left\{\frac{\triangle_{2}+\bar{a}_{22}}{\bar{a}_{21}}\right\} .
$$

From (2.6) and (2.9), we obtain

$$
\begin{aligned}
x_{1}(t) \leq & \left.x_{1}\left(\xi_{1}\right)+\int_{0}^{\omega}\left|x_{1}^{\prime}(t)\right| d t<\ln \left\{\frac{\triangle_{1}}{\bar{a}_{11}}\right\}+2 \sum_{k=1}^{q} \ln \left(1+b_{1 k}+h_{1 k}\right)\right):=H_{1}, \\
x_{2}(t) \leq & x_{2}\left(\xi_{2}\right)+\int_{0}^{\omega}\left|x_{2}^{\prime}(t)\right| d t<\ln \left\{\frac{\triangle_{2}+\bar{a}_{22}}{\bar{a}_{21}}\right\} \\
& \left.+2\left(\sum_{k=1}^{q} \ln \left(1+b_{2 k}+h_{2 k}\right)\right)+\bar{a}_{22} \omega\right):=H_{2} .
\end{aligned}
$$


On the other hand from (2.5) and (2.8)

$$
\int_{0}^{\omega}\left[a_{11}(t) e^{x_{1}(t)}+\frac{a_{12}(t) e^{x_{2}(t)+x_{1}(t)}}{a_{13}^{2}(t)}\right] d t \geq \triangle_{1} \omega,
$$

that is

$$
\bar{a}_{11} e^{x_{1}\left(\eta_{1}^{+}\right)}+\overline{\left(\frac{a_{12}}{a_{13}^{2}}\right)} e^{H_{1}+H_{2}} \geq \triangle_{1}
$$

then

$$
x_{1}\left(\eta_{1}^{+}\right) \geq \ln \left\{\frac{\triangle_{1}-\overline{\left(\frac{a_{12}}{a_{13}^{2}}\right)} e^{H_{1}+H_{2}}}{\bar{a}_{11}}\right\},
$$

and hence

$$
\begin{aligned}
& \left.x_{1}(t) \geq x_{1}\left(\eta_{1}^{+}\right)-\int_{0}^{\omega}\left|x_{1}^{\prime}(t)\right| d t \geq \ln \left\{\frac{\triangle_{1}-\overline{\left(\frac{a_{12}}{a_{13}^{2}}\right)} e^{H_{1}+H_{2}}}{\bar{a}_{11}}\right\}-2 \sum_{k=1}^{q} \ln \left(1+b_{1 k}+h_{1 k}\right)\right) \\
& :=H_{3} .
\end{aligned}
$$

Similarly, one can derive that

$$
\begin{gathered}
\int_{0}^{\omega}\left[a_{21}(t) e^{x_{2}\left(\eta_{2}^{+}\right)}-\frac{a_{22}(t) e^{2 H_{3}}}{a_{13}^{2}(t)+e^{2 H_{1}}}\right] d t \geq \triangle_{2} \omega . \\
x_{2}\left(\eta_{2}^{+}\right) \geq \ln \left\{\frac{\left(\frac{a_{22} e^{2 H_{3}}}{a_{13}^{2}+e^{2 H_{1}}}\right)}{\bar{a}_{21}}+\triangle_{2}\right\},
\end{gathered}
$$

then

$$
\begin{aligned}
x_{2}(t) \geq & x_{2}\left(\eta_{2}^{+}\right)-\int_{0}^{\omega}\left|x_{1}^{\prime}(t)\right| d t \geq \ln \left(\frac{\left(\frac{a_{22} e^{2 H_{3}}}{a_{13}^{2}+e^{2 H_{1}}}\right)}{\bar{a}_{21}}+\triangle_{2}\right. \\
& -2\left(\sum_{k=1}^{q} \ln \left(1+b_{2 k}+h_{2 k}\right)+\bar{a}_{22} \omega\right):=H_{4},
\end{aligned}
$$

which, together with (2.10) and (2.11), implies 


$$
\begin{gathered}
\sup _{t \in[0, \omega]}\left|x_{1}(t)\right|<\max \left\{\left|H_{1}\right|,\left|H_{3}\right|\right\}:=M_{1}, \\
\sup _{t \in[0, \omega]}\left|x_{2}(t)\right|<\max \left\{\left|H_{2}\right|,\left|H_{4}\right|\right\}:=M_{2} . \\
\|x\|_{C} \leq\left(M_{1}^{2}+M_{2}^{2}\right)^{1 / 2}:=M
\end{gathered}
$$

Clearly, $M_{1}$ and $M_{2}$ are independent of $\lambda$.

Now consider the following system of algebraic equations

$$
\begin{gathered}
\triangle_{1}-\bar{a}_{11} e^{x_{1}}-\mu \overline{\left(\frac{a_{12}(t) e^{x_{1}+x_{2}}}{a_{13}^{2}(t)+e^{2 x_{1}}}\right)}=0 \\
\triangle_{2}-\bar{a}_{21} e^{x_{2}}+\overline{\left(\frac{a_{22}(t) e^{2 x_{1}}}{a_{13}^{2}(t)+e^{2 x_{1}}}\right)}=0
\end{gathered}
$$

where $x=\left(x_{1}, x_{2}\right)^{T} \in R^{2}$ and $\mu \in[0,1]$ is a parameter. Using the similar technique and the previous estimates, we get $\bar{H}_{3}<x_{1}<\bar{H}_{1}, \bar{H}_{4}<x_{2}<\bar{H}_{2}$, where

$$
\begin{gathered}
\bar{H}_{1}=\ln \left\{\frac{\triangle_{1}}{\bar{a}_{11}}\right\}, \quad \bar{H}_{2}=\ln \left\{\frac{\triangle_{2}+\bar{a}_{22}}{\bar{a}_{21}}\right\}, \\
\bar{H}_{3}=\ln \left\{\frac{\triangle_{1}-\overline{\left(\frac{a_{12}}{a_{13}^{2}}\right)} e^{\bar{H}_{1}+\bar{H}_{2}}}{\bar{a}_{11}}\right\}, \quad \bar{H}_{4}=\ln \left\{\frac{\left(\frac{a_{22} e^{2 \bar{H}_{3}}}{a_{13}^{2}+e^{2 \bar{H}_{1}}}\right)+\triangle_{2}}{\bar{a}_{21}}\right\} .
\end{gathered}
$$

Take $\bar{M}_{1}=\max \left\{\left|\bar{H}_{1}\right|,\left|\bar{H}_{3}\right|\right\}, \bar{M}_{2}=\max \left\{\left|\bar{H}_{2}\right|,\left|\bar{H}_{4}\right|\right\}$, it is easy to know that $\bar{M}_{i}$, $i=1,2$ is independent of $\mu$ such that

$$
\|x\| \leq\left(\bar{M}_{1}^{2}+\bar{M}_{2}^{2}\right)^{1 / 2}:=\bar{M} .
$$

so $\bar{M}$ is independent of $\mu$. It is proved that $\|x\|_{C} \leq \bar{M}$ for every solution $x=$ $\left(x_{1}, x_{2}\right)$ of (2.14). Now, we take $M^{*}>\max \{M, \bar{M}\}$ such that $\left\|x\left(t_{k}+0\right)\right\|<M^{*}$. Let $\Omega:=\left\{x=\left(x_{1}, x_{2}\right) \in X \mid\|x\|_{C}<M^{*}\right\}$. It is clear that $L x \neq \lambda N x$ for $x \in \partial \Omega$ and $\lambda \in(0,1)$, thus $\Omega$ verifies the requirement (a) in Lemma 2.1. When $x \in$ $\partial \Omega \cap \operatorname{Ker} L=\partial \Omega \cap R^{2}, x$ is a constant vector in $R^{2}$ with $\|x\|=M$. Then from (2.15)

$$
\left.Q N x=\left(\begin{array}{c}
\triangle_{1}-\bar{a}_{11} e^{x_{1}}-\overline{\left(\frac{a_{12}(t) e^{x_{1}+x_{2}}}{a_{13}^{2}(t)+e^{2 x_{1}}}\right)} \\
\triangle_{2}-\bar{a}_{21} e^{x_{2}}+\overline{\left(\frac{a_{22}(t) e^{2 x_{1}}}{a_{13}^{2}(t)+e^{2 x_{1}}}\right)}
\end{array}\right),(0 \cdots 0)_{2 \times 1}\right) \neq 0 .
$$


Now let us consider homotopy $h_{\mu}(x)=\mu Q N x+(1-\mu) G x, \mu \in[0,1]$, where

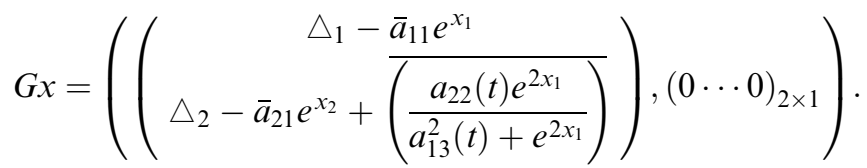

We know that $0 \notin h_{\mu}(\partial \Omega \cap \operatorname{Ker} L)$ for $\mu \in(0,1)$ and noting that $J=I$, hence

$$
\operatorname{deg}(J Q N, \Omega \cap \operatorname{Ker} L, 0)=\operatorname{deg}(G, \Omega \cap \operatorname{Ker} L, 0) \neq 0
$$

by the property of homotopy invariance of topological degree. By now we have proved that $\Omega$ verifies all requirements of Lemma 2.1, then $L x=N x$ has at least one solution in Dom $L \cap \bar{\Omega}$, i.e., (1.4) has at least one $\omega$-periodic solution in Dom $L \cap \bar{\Omega}$, say $x=\left(x_{1}^{*}(t), x_{2}^{*}(t)\right)^{T}$. Set $y^{*}=\left(y_{1}^{*}(t), y_{2}^{*}(t)\right)^{T}=\left(e^{x_{1}^{*}(t)}, e^{x_{2}^{*}(t)}\right)^{T}$, then $y^{*}=\left(y_{1}^{*}(t), y_{2}^{*}(t)\right)^{T}$ is one positive $\omega$-periodic solution of system (1.2). The proof is complete.

\section{REFERENCES}

[1] Anokhin, A. V., Berezansky, L., Braverman, E., Exponential stability of linear delay impulsive differential equations, J. Math. Anal. Appl., 1995, 193: 923-941.

[2 $]$ Bainov, D. D., Covachev, V., Stamova, I., Stability under persistent disturbances of impulsive differential-difference equations of neutral type, J. Math. Anal. Appl., 1994, 187: 790-808.

[ 3 ] Du, X. W., Yuan, S. L., A study on a kind of periodic model with III response function of three groups, Journal of engineering mathematics, 2000, 17(3): 139-142.

[ 4 ] Fan, M., Wang, K., Global Existence of Positive Periodic Solutions of Periodic PredatorPrey System with Infinite Delays, J. Math. Anal. Appl., 2001, 262(1): 1-11.

[5] Fan, M., Wang, K., Periodicity in a Delayed Ratio-Dependent PredatorPrey System, J. Math. Anal. Appl., 2001, 262(1): 179-190.

[6] FAN, M., WANG, K., Periodic solutions of nonautonomous discrete time ratio-dependent predator-prey system, Mathematical and Computers Modelling, 2002, 35: 951-961.

[ 7 ] Gaines, R. E., Mawhin, J. L., Coincidence degree and nonlinear differential equations, Springer-Verlag, Berlin, 1977.

[ 8 ] Holling, C. S., The functional response of predators to prey density and its role in mimicry and population regulation, Mem. Ent. Soc. Can., 1965, 46: 1-60.

[9] JIA, J. W., Persistence and periodic solution for the non-autonomous predator-prey system with type III functional resposne[J], 2001, 16(1): 59-62.

[10] JIN, Z., The study for ecological and epidemical models influenced by impulses, Doctoral Dissertation, Xi'an Jiaotong Uiversity, 2001.

[11] Kunang, Y., Beretta, E., Global qualitative analysis of a ratio-dependent predator-prey system[J], J. Math. Biol., 1998, 36(3): 389-406.

[12] Lakshmikantham, V., Bainov, D. D., Simeonov, P. S., Theory of Impulsive Differential Equations, World Scientific, Singapore (1989).

[13] Samoilenko, A. M., Perestyuk, N. A., Differential Equations with Impulse Effect, Visca Skola, Kiev, 1987 (in Russian).

[14] SHEN, J. H., On some asymptotic stability results of impulsive integro-differential equations, Chinese Math. Ann., 1996, 17A: 759-765. 
[15] SHEn, J. H., The existence of non-oscillatory solutions of delay differential equations with impulses, Appl. Math. Comput., 1996, 77: 156-165.

[16] Shen, J. H., YAN, J. R., Razumikhin type stability theorems for impulsive functional differential equations, Nonlinear Anal. TMA. 1998, 33: 519-531.

[17] Xu, R., Chen, L. S., Persistence and global stability for three-species ratio-dependent predatorprey system with time delays[J], J. Sys. Sci. and Math. Scis., 2001, 21(2): 204-212 (in Chinese).

[18] Yu, J. S., Zhang, B. G., Stability theorems for delay differential equations with impulses, J. Math. Anal. Appl., 1996, 199: 162-175.

[19] Zhang, X. Y., Bai, L., Fan, M. AND WANG, K., Existence of positive periodic solution for predator-prey difference system with Holling III functional response, Mathematica Applicata, 2002, 15(3): 25-31.

School of Mathematics and Statistics, and

Key Laboratory for Vegetation Ecology of the Education Ministry

NORTHEAST NORMAL UNIVERSITY

5268 Renmin Street, Changchun, Jilin, 130024

The People's Republic of China

E-mail:mfan@nenu.edu.cn 